Medical Research Archives. Volume 5, issue 6. June 2017.

Utilizing Patient Hope and Outcome Expectations

\title{
Utilizing Patient Hope and Outcome Expectations to Facilitate Treatment Gains
}

\author{
Authors \\ Susannah R. Parkin \\ Parksus2@isu.edu \\ Joshua K. Swift \\ joshua.keith.swift@gmail. \\ $\underline{\text { com }}$
}

\begin{abstract}
Research indicates that patients' hope and positive outcome expectations are associated with favorable treatment outcomes. The importance of hope and expectations are discussed in relation to psychotherapy in addition to broader healthcare settings such as pain management and surgery. Five suggestions for promoting hope and positive outcome expectations for patients are provided including presenting a convincing treatment rational, sharing successful case examples and the belief that treatment will work, increasing the patient's faith in the health care provider, making sure patients' expectations are not overly optimistic, and allowing patients to have input into treatment decision-making. Keywords: patient; expectations; hope.
\end{abstract}


Medical Research Archives. Volume 5, issue 6. June 2017.

Utilizing Patient Hope and Outcome Expectations

Utilizing Patient Hope and Outcome Expectations to Facilitate Treatment Gains

An old joke states that two people get a physical examination. One of the people is healthy and the other has a terminal illness. The hospital gets the results mixed up so the healthy person gets the terminal diagnosis and the terminally ill person gets the healthy diagnosis. The healthy person dies and the sick person lives. Although not always as extreme as this example, patients' hope and expectations do serve an important role in the health care setting.

Hope is the belief that one's goals can be accomplished through specific pathways and by way of one's motivation. ${ }^{1}$ Although similar to optimism in the sense that both include cross-situational beliefs of a positive outcome, they differ because optimism does not include specific pathways or motivation to achieve that positive outcome. Hope is also similar to selfefficacy theory ${ }^{2}$, which proposes the importance of either one's belief that a particular behavior will produce a desired outcome (pathways) or one's belief that he or she can undertake the behavior to produce the desired outcome (agency). However, they differ because hope requires both pathways and agency. So, hope in medicine can be thought of as the variable that provides patients with motivation to engage in treatment to produce a desired outcome. This type of hope is similar to outcome expectations, which are patients' prognostic beliefs about the likelihood for treatment success. ${ }^{3}$

\section{Findings from Psychotherapy}

Within the field of psychotherapy, hope and expectations have been shown to influence both the process and outcomes of treatment. Frank and Frank (1991) describe outcome expectations as the pivotal variable for therapeutic change. ${ }^{4}$ That is, they postulate that patients seek therapy when they are in a state of demoralization and therapy serves as a hope-inspiring mechanism that presents a pathway through which they can solve their problems. If patients believe that therapy will help them, they are more likely to participate in therapy, which, in turn, leads to an improvement in well-being and a reduction of symptoms. Research supports this theory, as outcome expectations about the utility of treatment have been found to influence attitudes about seeking help, which, in turn, are associated with help-seeking behavior., ${ }^{5,6}$

Research supports the theory of hope in psychotherapy, as patients' outcome expectations have been found to be directly related to treatment initiation, treatment completion, treatment processes and eventual treatment outcomes in psychotherapy. For example, Swift and colleagues (2012) have found that patients are more likely to show up for initial appointments when they have higher levels of hope and more positive outcome expectations. ${ }^{5}$ As another example, Elkin and colleagues (1999) found that when patients were matched to a treatment they thought would be effective, only 5\% dropped out; however, when they were assigned to a treatment they believed would be less effective, $21 \%$ dropped out. ${ }^{7}$ Although these findings demonstrate that it 
is helpful for patients to have positive expectations about treatment, research also indicates that expectations should not be overly optimistic. Nock and Kazdin (2001) found a curvilinear relationship between optimism in treatment and premature termination, such that there was an increased likelihood for drop out both when expectations were pessimistic or when they were overly optimistic. ${ }^{8}$ At the overly optimistic end, patients may get discouraged when treatment does not work as quickly as they were expecting. All in all, a metaanalysis by Constantino and colleagues (2011) found a significant relationship ( $r=$ .12) between expectations and treatment outcomes, with positive expectations being linked to positive outcomes. ${ }^{3}$

One potential explanation for the association between positive expectations and positive outcomes is the therapeutic alliance. Edward Bordin (1979) described the alliance as the affective and collaborative patient-therapist relationship. ${ }^{9}$ The abundance of research supporting the power of the alliance has led to the wellaccepted notion that a strong alliance is necessary for therapeutic change to occur. ${ }^{10}$ A study by Yoo, Hong, Sohn, and O'Brien (2014) revealed that the alliance mediated and moderated the relationship between patients' expectations of psychotherapy success. $^{11}$ In other words, the findings demonstrated that patients with positive outcome expectations were more able to form a strong alliance with their provider and this strong alliance led to increased therapeutic change. The authors also found that the relationship between expectations, alliance, and treatment outcome was strongest for patients with higher levels of outcome expectations as compared to patients with lower levels of outcome expectations.

\section{Applications to Medicine}

Testing placebos is a common method for studying hope and expectations in health care settings. A placebo treatment is an inert treatment that lacks the active ingredients of the intervention. ${ }^{12}$ Because a placebo treatment is thought to be inert, patient improvement in placebo conditions is thought to be due to patient hope and positive outcome expectations.

Interestingly, research findings indicate that a significant portion of patients do in fact experience improvements while on placebo treatments. ${ }^{13}$ For example, in a meta-analysis that included 182 studies and 36,385 patients, Walsh, Siedman, Sysko, and Gould (2002) found a 37.3\% response rate for placebo antidepressants. ${ }^{14}$ Responses to placebos may be even higher when they are made to mimic the side effects of the active comparison drugs. ${ }^{15,16}$ In fact, research suggests that placebos may account for more than $75 \%$ of the efficacy in antidepressant medications. ${ }^{17,18,19}$

The placebo effect has also been largely observed in other fields of medicine, such as pain reduction. One study by Levine and Gordon (1984) found that telling patients that they were taking a pain medication was as effective as $8 \mathrm{mg}$ of morphine. $^{20}$ Another study by Amanzio, Pollo, Maggi, and Benedetti (2001) found that a placebo was as effective as $0.14 \mathrm{mg}$ of buprenoprine, $31 \mathrm{mg}$ of tramadol, $12 \mathrm{mg}$ of ketorolac, and $521 \mathrm{mg}$ of metamizol for patients after thoracic surgery. ${ }^{21}$ The same 
authors also found that hidden pain medication injections were less effective than were open injections (in view of the patient), which also demonstrates the role of hope and expectations in the treatment process. $^{21}$

The placebo effect has even been shown to occur in surgery procedures. A study by McRae and colleagues (2004) examined quality of life improvements in patients with advanced Parkinson's disease. $^{22}$ One group of the patients received a transplantation of human embryonic dopamine neurons and the other group received a sham surgery. Patients did not know which surgery group they were in, but following the surgery they were asked whether they thought they received the transplant surgery or the sham surgery. Regardless of what surgery they received, patients who believed they received the transplant surgery reported better physical functioning and more social support than did the patients who believed they received the sham surgery. Another study by Mosley and colleagues (2002) examined patients' reported symptom relief after arthroscopic knee surgery. ${ }^{23}$ Patients with osteoarthritis of the knee were randomly assigned to receive arthroscopic lavage, arthroscopic debridement, or sham surgery. Following the surgery, the sham surgery group reported similar levels of functioning as patients in the arthroscopic lavage and debridement groups.

Outside of the placebo effect, patient expectations in general have been linked to medical outcomes. A meta-analysis of 16 medical studies by Mondloch, Cole, and Frank (2001) revealed small to large effect sizes for the relationship between patient expectations and patient outcomes. ${ }^{24}$ This effect was present in conditions ranging from myocardial infarction to chronic pain and laparoscopic surgery. Specifically, across conditions, when patients believed they were going to get better, they were more likely to actually recover.

\section{Strategies for Building Hope and Expectations}

Building hope and expectations in patients can take place at all stages of the treatment process. Further, multiple strategies exist to build the right amount of hope and positive outcome expectations in patients. The following five strategies are recommended.

\subsection{Provide a convincing treatment rationale}

In order to build hope in patients, providers should provide patients with a convincing rationale for why the treatment will work. In a study examining rationale delivery, Kazdin and Krouse (1983) found that patients believed in treatments more when they were presented as being tested in clinical trials and supported by the scientific research. ${ }^{25}$ Beliefs in treatment credibility are one aspect of hope, which can then lead to positive treatment outcomes. A study by Addis and Jacobson (2000) found that patients' perceived treatment creditability was associated with treatment engagement (i.e., homework completion) and overall outcomes. ${ }^{26}$ Another study by Haanstra and colleagues (2015) found a strong correlation between treatment creditability and expectancy in a sample of patients undergoing hip and knee arthroplasty. ${ }^{27}$

\subsection{Use successful case examples}


Kazdin and Krouse (1983) also found that the use of successful case examples when presenting a treatment to patients can also lead to positive patient expectations. $^{25}$ Thus, providers can share with their patients examples of cases where the treatment has worked in the past. This works particularly well when the patient in the previous case example is described as being similar to the current patient. Additionally, providers can express their belief that the treatment will work this time around for the current patient.

\subsection{Increase the patient's faith in the provider}

It is important for patients to believe that their providers can help them. Hoyt (1996) examined the relationship between beliefs about provider credibility and treatment outcomes. ${ }^{28}$ In that meta-analysis, patients' perception of provider creditability were significantly related to later patient satisfaction, attitude change, and behavior change. In another more recent study, Paulsel, McCroskey, and Richmond (2006) found that patient satisfaction was most strongly linked to their perceptions of their health care providers' competence and caring. ${ }^{29}$ One way to increase a patient's faith in the provider is by building a positive patient-doctor relationship through open communication. Bass and colleagues (1986) found that agreement between the patient and doctor on the nature of the patient's problem was related to a decrease in the patient's symptoms. ${ }^{30}$ Another study by Stewart (1995) found that the quality of communication between patients and doctors influenced patients' outcomes. ${ }^{31}$

\subsection{Provide positive and realistic outcome expectations}

As previously mentioned, a curvilinear relationship between optimism in treatment and premature drop out has been found in the literature, where an increased likelihood for drop out exists both when expectations are pessimistic or overly optimistic. ${ }^{8}$ Consequently, it is important to communicate to the patient expectations that are both positive and realistic. For example, Swift and Callahan (2011) found that patients were much less likely to drop out when they were provided realistic education about the likely duration of treatment. ${ }^{32}$

\subsection{Allowing the patients to have a choice}

An interesting example of the effects of patient choice can be found in a study conducted by Rose, Geers, Rasinki, and Fowler (2012). ${ }^{33}$ In this study participants were instructed to apply ointment to their hands before submerging them in ice water. Participants were told that there were two types of ointment: one blocked pain receptors and the other warmed the hand. In reality, both ointments were inert. The participants who were allowed to choose which ointment they used reported less pain from the ice water than participants who did not choose their ointment. These findings tell us patient preference matters, likely because patients prefer treatments that they think will work. Research indicates that when patients are given say into the treatment they receive, they are more likely to initiate that treatment, less likely to drop out, and more likely to make positive gains. ${ }^{34,35}$ 


\section{Conclusions}

Patients' hope and outcome expectations have been linked to positive treatment outcomes across health care disciplines. Thus, medical providers should work to utilize this patient variable to maximize the likelihood of treatment success. Healthcare providers may be able to promote hope and positive expectations in their patients by providing their patients with a convincing treatment rational, sharing successful case examples and their belief that the treatment will work for their patients, increasing their patients' faith in them as a competent provider, making sure patients do not hold overly optimistic expectations, and allowing patients to have a say in the treatment decision-making process. 


\section{References}

1. Snyder, CR. (1995). Conceptualizing, measuring, and nurturing hope. Journal of Counseling \& Development, 73 (3), 355-360. doi:10.1002/j.15566676.1995.tb01764.x

2. Bandura, A. (1977). Self-efficacy: Toward a unifying theory of behavioral change. Psychol Rev, 84 (2), 191-215.

3. Constantino, M J, Glass, CR, Arnkoff, DB, Ametrano, RM, \& Smith, JZ. (2011).Expectations. In J. C. Norcross (Ed.), Psychotherapy relationships that work: Evidence based responsiveness (2nd Edition, pp. 354-376). New York, NY: Oxford University Press.

4. Frank, JD, \& Frank, JB. (1991). Persuasion and healing: A comparative study of psychotherapy (3rd ed.). Baltimore, MD: Johns Hopkins University Press.

5. Swift, JK, Whipple, JL, \& Sandberg, P. (2012). A prediction of initial appointment attendance and initial outcome expectations. Psychotherapy, 49 (4), 549-556. doi:10.1037/a0029441

6. Vogel, DL, Wester, SR, Wei, M, \& Boysen, GA. (2005). The role of outcome expectations and attitudes on decisions to seek professional help. Journal of Counseling Psychology, 52 (4), 459-470. doi:10.1037/00220167.52.4.459.

7. Elkin, I, Yamaguchi, JL, Arnkoff, DB, Glass, CR, Sotsky, SM, \& Krupnick, JL. (1999). 'Patient-treatment fit' and early engagement in therapy. Psychotherapy Research, 9 (4), 437-451. doi:10.1093/ptr/9.4.437
8. Nock, MK, \& Kazdin, AE. (2001). Parent expectancies for child therapy: Assessment and relation to participation in treatment. Journal of Child and Family Studies, 10 (2), 155-180. doi:10.1023/A:1016699424731

9. Bordin, E. (1979). The generalizability of the psychoanalytic concept of the working alliance. Psychotherapy: Theory, Research and Practice, 16 (3), 252-260.

10. Safran, JD, Muran, JC, Samstag, LW, \& Stevens, C. (2002). Repairing alliance ruptures. In J. C. Norcross (Ed.), Psychotherapy relationships that work: Therapists contributions and responsiveness to patients (pp. 235254). New York: Oxford University Press.

11. Yoo, S, Hong, S, Sohn, N, \& O'Brien, KM. (2014). Working alliance as a mediator and moderator between expectations for counseling success and counseling outcome among Korean patients. Asia Pacific Education Review, 15, 271-281. doi:10.1007/s 12564-014-9320-2

12. Shapiro, AK, \& Shapiro, E. (1997). The powerful placebo: From ancient priest to modern physician. Baltimore, MD: Johns Hopkins University Press.

13. Greenberg, RP. (2016). The rebirth of psychosocial importance in a drugfilled world. Am Psychol, 71 (8), 781791.

14. Walsh, BT, Seidman, SN, Sysko, R, \& Gould, M. (2002). Placebo response in studies of major depression: Variable, substantial, and growing. JAMA, 287 
(14),

1840-1847.

doi:10.1001/jama.287.14.1840

15. Greenberg, RP \& Fisher, S. (1994). Suspended judgment. Seeing through the double-masked design: A commentary. Control Clin Trials, 15 (4), 244-246. doi:10.1016/01972456(94)90041-8

16. Greenberg, RP \& Fisher, S. (1997). Mood-mending medicines: Probing drug, psychotherapy and placebo solutions. In S. Fisher \& R. P. Greenberg (Eds.), From placebo to pancea: Putting psychiatric drugs to the test (pp. 115-172). New York, NY: Wiley.

17. Khan, A, Warner, HA, \& Brown, WA. (2000). Symptom reduction and suicide risk in patients treated with placebo in antidepressant clinical trials: An analysis of the Food and Drug Administration database. Arch Gen Pyschiatry, 57 (4), 311-317. http://dx.doi.org/10.1001/ archpsyc.57.4.311

18. Kirsch, I. (2014). Antidepressants and the placebo effect. Zeitschrift fur Psychologie mit Zeitschrift fur Angewandte Psychologie, 222 (3), 128 -134. http://dx.doi.org/10.1027/21512604/a000176

19. Kirsch, I, Moore, TJ, Scoboria, A, \& Nicholls, SS. (2002). The emperor's new drugs: An analysis of antidepressant medication data submitted to the U.S. food and drug administration. Prevention \& Treatment, 5 (1), 23. http://dx.doi.org/10.1037//15223736.5.0023a
20. Levine, JD, \& Gordon, NC. (1984). Influence of the method of drug administration on analgesic response. Nature, 312 (5996), 755-756.

21. Amanzio, M, Pollo, A, Maggi, G, \& Benedetti, F. (2001). Response variability to analgesics: A role for nonspecific activation of endogenous opioids. Pain, 90 (3), 205-215.

22. McRae, C, Cherin, E, Yamazaki, TG, Diem, G, Vo, AH, Russell, D, \& ... Freed, CR. (2004). Effects of perceived treatment on quality of life and medical outcomes in a double-blind placebo surgery trial. Arch Gen Psychiatry, 61 (4), 412-420. doi:10.1001/archpsyc.61.4.412

23. Moseley, JB, O’Malley, K, Petersen, NJ, Menke, TJ, Brody, BA, Kuykendall, DH, \& ...Wray, NP. (2002). A controlled trial of arthroscopic surgery for osteoarthritis of the knee. The New England Journal of Medicine, 347, 81-88. doi:10.1056/NEJMoa013259

24. Mondloch, MV, Cole, DC, \& Frank, JW. (2001). Does how you do depend on how you think you'll do? A systematic review of the evidence for a relation between patients' recovery expectations and health outcomes. CMAJ, 165 (2), 174-9.

25. Kazdin, AE, \& Krouse, R. (1983). The impact of variations in treatment rationales on expectancies for therapeutic change. Behavior Therapy, 14 (5), 657-671. doi:10.1016/S00057894(83)80058-6

26. Addis, ME, \& Jacobson, NS. (2000). A closer look at the treatment rationale 
and homework compliance in cognitive-behavioral therapy for depression. Cognitive Therapy and Research, 24 (3), 313-326. doi:10.1023/A:1005563304265

27. Haanstra, TJ., Tilbury, C, Kamper, SJ, Tordoir, RL, Vliet Vlieland, TPM, Nelissen, RGHH, \&...Ostelo, RW. (2015). Can optimism, pessimism, hope, treatment creditability and treatment expectancy be distinguished in patients undergoing total hip and total knee arthroplasty. PLOS ONE, 10: e0133730.

doi: 10.1371/journal.pone.0133730

28. Hoyt, WT. (1996). Antecedents and effects of perceived therapist credibility: A meta-analysis. Journal of Counseling Psychology, 43 (4), 430447. doi:10.1037/0022-0167.43.4.430

29. Paulsel, ML, Richmond, VP, McCroskey, JC, \& Cayanus, JL. (2005). The relationships of perceived health professionals' communication traits and creditability with perceived patient confidentiality. Communication Research Reports, 22 (2), 129-142.

30. Bass, MJ, Buck, C, Turner, L, Dickie, G, Pratt, G, \& Robinson, HC. (1986). The physician's actions and the outcome of illness in family practice. $J$
Fam Pract, 23 (1), 43-47.

31. Stewart MA. (1995). Effective physician-patient communication and health outcomes: A review. CMAJ, 152 (9), 1423-1433.

32. Swift, JK, Callahan, JL. (2011). Decreasing treatment dropout by addressing expectations for treatment length. Psychotherapy Research, 21 (2), 193-200. doi: 10.1080/10503307.2010.541294.

33. Rose, JP, Geers, AL, Rasinski, HM, \& Fowler, SL. (2012). Choice and placebo expectation effects in the context of pain analgesia. J Behav Med, 35 (4), 462-470. doi:10.1007/s10865-0119374-0

34. King, M, Nazareth, I, Lampe, F, Bower, P, Chandler, M, Morou, M, \& ... Lai, R. (2005). Impact of Participant and Physician Intervention Preferences on Randomized Trials: A Systematic Review. JAMA, 293 (9), 1089-1099. doi:10.1001/jama.293.9.1089

35. Swift, JK, Callahan, JL, \& Vollmer, BM. (2011). Preferences. In J. C. Norcross (Ed.), Psychotherapy relationships that work: Evidence based responsiveness (2nd Edition, pp. 301315). New York, NY: Oxford University Press. 